Research Article

\title{
Quantum Propagator Derivation for the Ring of Four Harmonically Coupled Oscillators
}

\author{
James Mendoza Gallo ${ }^{1, a, *}$ and Bienvenido Masirin Butanas Jr. ${ }^{1, b}$ \\ ${ }^{1}$ Theoretical Physics Group, Department of Physics, Central Mindanao University \\ Musuan, Maramag, Bukidnon, 8710 Philippines \\ e-mail: ${ }^{a}$ gallojames70@gmail.com and b bien.butanas@.cmu.edu.ph \\ * Corresponding Author
}

\begin{abstract}
The ring model of the coupled oscillator has enormously studied from the perspective of quantum mechanics. The research efforts on this system contribute to fully grasp the concepts of energy transport, dissipation, among others, in mesoscopic and condensed matter systems. In this research, the dynamics of the quantum propagator for the ring of oscillators was analyzed anew. White noise analysis was applied to derive the quantum mechanical propagator for a ring of four harmonically coupled oscillators. The process was done after performing four successive coordinate transformations obtaining four separated Lagrangian of a one-dimensional harmonic oscillator. Then, the individual propagator was evaluated via white noise path integration where the full propagator is expressed as the product of the individual propagators. In particular, the frequencies of the first two propagators correspond to degenerate normal mode frequencies, while the other two correspond to non-degenerate normal mode frequencies. The full propagator was expressed in its symmetric form to extract the energy spectrum and the wave function.
\end{abstract}

Keywords: white noise analysis, path integrals, coupled harmonic oscillators

\section{Penurunan Propagator Kuantum untuk Cincin pada Empat Osilator Harmonik Berpasangan}

\begin{abstract}
Abstrak
Model cincin dari osilator harmonik berpasangan telah banyak dipelajari dalam perspektif mekanika kuantum. Penelitian pada sistem ini berkontribusi untuk memahami sepenuhnya konsep perpindahan energi, disipasi, antara satu dengan yang lain, pada sistem mesoskopik dan zat mampat. Pada penelitian ini, peneliti menganalisis dinamika dari propagator kuantum untuk cincin osilator baru. Penelitian ini bertujuan untuk menganalisis propagator mekanika kuantum untuk cincin dari osilator-osilator. Analisis white noise telah diaplikasikan untuk menurunkan propagator mekanika kuantum untuk cincin dari empat osilator harmonik berpasangan. Proses ini dilakukan setelah melakukan empat transformasi koordinat berturut-turut yang memperoleh empat Lagrangian terpisah dari osilator harmonik satu dimensi. Kemudian, propagator individual dievaluasi melalui integral jalur white noise yang mana propagator penuh dinyatakan sebagai produk dari propagator individual. Secara khusus, frekuensi dari dua
\end{abstract}

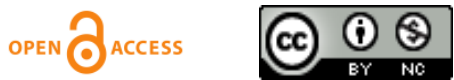


propagator pertama berhubungan dengan degenerasi frekuensi mode normal, sedangkan dua lainnya berhubungan dengan frekuensi mode normal yang tidak terdegenerasi. Propagator penuh dinyatakan dalam bentuk simetrisnya untuk mengekstraksi spektrum energi dan fungsi gelombang.

Kata Kunci: analisis white noise, path integral, osilator harmonik berpasangan

PACS: 02.50.Ey, 03.65.-w, 05.45.Xt

(C) 2019 Jurnal Penelitian Fisika dan Aplikasinya (JPFA). This work is licensed under CC BY-NC 4.0

Article History: Received: February 6, 2019

Accepted: October 18, 2019
Approved with minor revision: August 7, 2019

Published: December 31, 2019

How to cite: Gallo J M and Butanas Jr B M. Quantum Propagator Derivation for the Ring of Four Harmonically Coupled Oscillators. Jurnal Penelitian Fisika dan Aplikasinya (JPFA). 2019; 9(2): 92-104. DOI: https://doi.org/10.26740/jpfa.v9n2.p92-104.

\section{INTRODUCTION}

Studying the dynamics of coupled harmonic oscillators has been the subject of great interest these past decades. This model is found in many applications of quantum and nonlinear physics [1-4], condensed matter physics [5], and biophysics [6-7].

Several mathematical explorations concerning coupled oscillations, including the linear chains and ring geometry, have been addressed [8-20]. Researches conducted by Hong-Yi [9] and Butanas [19] focus on analyzing the dynamics of three coupled oscillators by solving the wave function and quantum propagator. This three-body system became the study of interest because the system avoids any "edge effects", with which one can easily employ its symmetrical nature when analyzing its dynamics.

The present work extends the ideas of Hong-Yi [9] and Butanas [19] by describing first its dynamics in the case of four identical masses. The geometry of the system is illustrated in Figure 1. The extension of such a system posits unique importance especially in the field of physics. It can be applied to systems of $N$-coupled oscillators coupled with an environment, which can be used to model quantum transport of energy excitation in solid-state and biological systems [20]. In investigating the dynamics of the said system, the method of the Feynman path integral is utilized.

Path integration was developed by Feynman [21], with the realization of summing-over-all possible histories of the particle's path.

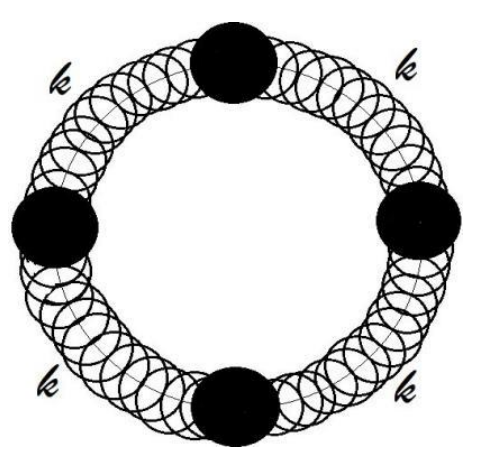

Figure 1. System of Ring of Four Harmonically Coupled Oscillators of Uniform Mass and Frequency

The formulation, however, has been known to be mathematically ill-defined due to the presence of the infinite-dimensional flat "measure". Various attempts were made in providing a rigorous foundation and one of these is the white noise analysis. 
White noise analysis is a mathematical framework used to provide the traditional path integral method a rigorous formulation [22-24]. This method was a joint development of Hida and Streit [25] as a novel approach to infinite-dimensional analysis.

Since its extensive development, the white noise analysis method became an important tool especially in the field of theoretical physics in describing the behavior of certain systems in quantum and statistical mechanics. Studies conducted [18-20, 26-30, 33-42] explicitly show the promise of white noise analysis in investigating both open and closed quantum systems due to its mathematical ease of use. Therefore, the research aims to derive quantum propagator for the ring of four harmonically coupled oscillators.

\section{METHOD}

This section provides the Lagrangian of the system which is the primary problem in solving the path integral. Moreover, the steps in evaluating the quantum mechanical propagator are presented.

\section{Four harmonically Coupled Oscillators}

The Lagrangian of four harmonically coupled oscillators as illustrated in Figure 1, is defined in Equation (1).

$$
\begin{aligned}
L & =\frac{1}{2 m}\left(p_{1}^{2}+p_{2}^{2}+p_{3}^{2}+p_{4}^{2}\right)+\frac{1}{2} m \omega^{2} x_{1}^{2} \\
& +\frac{1}{2} m \omega^{2} x_{2}^{2}+\frac{1}{2} m \omega^{2} x_{3}^{2}+\frac{1}{2} m \omega^{2} x_{4}^{2} \\
& +\lambda x_{1} x_{2}+\lambda x_{2} x_{3}+\lambda x_{3} x_{4}+\lambda x_{4} x_{1}
\end{aligned}
$$

where $x, p$, and $\omega$ are the corresponding positions, momenta and frequencies of the system, while the $\lambda$ 's are the real coupling constants of nearest-neighbor interactions.

\section{Coordinate Transformation}

Systems of coupled harmonic oscillators are easier to handle by incorporating first the coordinate transformation [17] to decouple the system. The transformation matrix, which is analogous to obtaining the normal modes of the system, is written in Equation (2).

$$
\left|\begin{array}{l}
x_{1} \\
x_{2}
\end{array}\right|=\left(\begin{array}{cc}
\cos \varphi & \sin \varphi \\
-\sin \varphi & \cos \varphi
\end{array}\right)\left|\begin{array}{l}
y_{1} \\
y_{2}
\end{array}\right|
$$

where $y_{1}$ and $y_{2}$ are the new coordinates. From this, the following relations can be obtained in Equations (3) and (4).

$$
\begin{gathered}
x_{1}=y_{1} \cos \varphi+y_{2} \sin \varphi \\
x_{2}=-y_{1} \sin \varphi+y_{2} \cos \varphi
\end{gathered}
$$

Differentiate Equations (3) and (4), then substitute these into the Lagrangian given for the system. Finally, by imposing the rotation angle in Equation (5).

$$
\varphi=\frac{(2 n+1) \pi}{4}
$$

where $n=0,1,2, \ldots$ helps to eliminate the system's couplings and obtain a newly defined Lagrangian. This process is repeated until all the couplings are decoupled and a separable Lagrangian is obtained. Hence, the quantum propagator for the system will be derived individually which leads the resulting full propagator to be the product of each of the propagators.

\section{Feynman Quantum Propagator as a White} Noise Functional

The summation-over-all histories as derived by Feynman [21] expresses the quantum propagator symbolically by Equation (6).

$$
K\left(x_{1}, x_{0} ; \tau\right)=\int \exp \left(\frac{i}{\hbar} S\right) D[x]
$$

where $S$ is the classical action and $D[x]$ is the infinite-dimensional flat "measure". The equation can be recast into the framework of white noise analysis by first parametrizing the 
trajectory of the particle containing the Brownian fluctuation [22-23] given by Equation (7).

$$
x(t)=x_{0}+\sqrt{\frac{\hbar}{m}} \int_{0}^{t} \omega(\tau) d \tau
$$

where $\hbar$ as the Planck's constant divided by $2 \pi, m$ is the mass of the particle being considered, and $\omega(\tau)$ as the Gaussian white noise variable representing the "velocity" of the Brownian motion. Taking the correspondence between the Lebesgue measure $D[x]$ and the Gaussian measure $d \mu(\omega)$ gives in Equation (8).

$D[x]=\lim _{N \rightarrow \infty} \prod_{j=1}^{N}\left(A_{j}\right) \prod_{j=1}^{N-1}\left(d x_{j}\right)=N d^{\infty} x$

with

$$
\begin{aligned}
N d^{\infty} x & \rightarrow N d^{\infty} \omega \\
& =N \exp \left[\frac{1}{2} \int_{0}^{t} \omega(\tau)^{2} d \tau\right] d \mu(\omega)
\end{aligned}
$$

with $N$ as some normalization constant. Furthermore, the endpoints the particle may take is fixed by introducing the Donsker delta function $\delta\left(x(t)-x_{1}\right)$, with its Fourier decomposition defined as Equation (10).

$$
\delta\left(x(t)-x_{1}\right)=\frac{1}{2 \pi} \int_{-\infty}^{\infty}\left[i \lambda\left(x(t)-x_{1}\right)\right] d \lambda
$$

such that at time $t$ the particle is located at $x_{1}$. Lastly, with the previous equations, the Feynman propagator is written in the context of white noise analysis as Equation (11).

$$
\begin{aligned}
K\left(x_{1}, x_{0} ; \tau\right)= & N \int \exp \left[\frac{i+1}{2} \int_{0}^{t} \omega(\tau)^{2} d \tau\right] \\
& \times \exp \left[-\frac{i}{\hbar} \int_{0}^{t} V(x) d \tau\right] \\
& \times \delta\left(x(t)-x_{1}\right) d \mu(\omega)
\end{aligned}
$$

The recasting of the Feynman path integration into the language of white noise analysis is summarized in Figure 2.
After evaluating the propagator of the system, one could then calculate the corresponding time-independent wave function by the symmetrization of the obtained propagator given by Equation (12).

$$
K=\sum \psi^{*}(x) \psi(0) e^{-\frac{i E t}{\hbar}}
$$

where $\psi(x)$ is the time-independent wave function, $\psi^{*}(0)$ is its conjugate and $E$ is the energy spectrum.

Feynman quantum propagator:

$$
K\left(x_{1}, x_{0} ; \tau\right)=\int \exp \left(\frac{i}{\hbar} S\right) D[x]
$$

Parametrization of paths:

$$
x(t)=x_{0}+\sqrt{\frac{\hbar}{m}} \int \omega(\tau) d \tau
$$

Make a correspondence between the Lebesgue measure and the Gaussian white noise measure:

$D[x]=d^{\infty} x \rightarrow d^{\infty} \omega$

$$
=\mathrm{N} \exp \left[\frac{1}{2} \int \omega(t)^{2} d t\right] d \mu(\omega)
$$

Fix the endpoints by introducing the Donsker delta function:

$$
\delta\left(x(t)-x_{1}\right)
$$

Feynman propagator in the context of white noise analysis:

$$
K=\int \mathrm{I} d \mu(\omega)
$$

with $I$ as the white noise functional.

Figure 2. Schematic Diagram of the Recasting of Feynman Propagator in the Context of White Noise Analysis 


\section{III.RESULTS AND DISCUSSION}

Quantum propagator derivation starts with defining the Lagrangian of the system being considered. For the circular system in Figure 1, the Lagrangian is formally written in the Equation (13).

$$
\begin{gathered}
L=\frac{1}{2} m\left(\dot{x}_{1}^{2}+\dot{x}_{2}^{2}+\dot{x}_{3}^{2}+\dot{x}_{4}^{2}\right)-\frac{1}{2} m \omega^{2} x_{1}^{2} \\
-\frac{1}{2} m \omega^{2} x_{2}^{2}-\frac{1}{2} m \omega^{2} x_{3}^{2}-\frac{1}{2} m \omega^{2} x_{4}^{2} \\
-\lambda x_{1} x_{2}-\lambda x_{2} x_{3}-\lambda x_{3} x_{4}-\lambda x_{4} x_{1}
\end{gathered}
$$

where $\lambda^{\prime} s$ are the real coupling constants of the nearest-neighbor interactions. Notice that Equation (13) contain coupling coordinates which are easier to handle with the aid of coordinate transformation [17], that is, by decoupling the coordinates one at a time. Considering first the decoupling of coordinates $x_{1}$ and $x_{2}$ with the matrix given by Equation (14).

$$
\left|\begin{array}{l}
x_{1} \\
x_{2}
\end{array}\right|=\left(\begin{array}{cc}
\cos \varphi & \sin \varphi \\
-\sin \varphi & \cos \varphi
\end{array}\right)\left|\begin{array}{l}
q_{1} \\
q_{2}
\end{array}\right|
$$

yields the new Lagrangian of the form given by Equation (15).

$$
\begin{aligned}
L= & \frac{1}{2} m\left(\dot{q}_{1}^{2}+\dot{q}_{2}^{2}+\dot{x}_{3}^{2}+\dot{x}_{4}^{2}\right)-\alpha q_{1}^{2}-\beta q_{2}^{2} \\
& -\gamma q_{1} q_{2}+v q_{1} x_{3}-\mu q_{2} x_{3}-\mu q_{1} x_{4} \\
& -v q_{2} q_{4}-\lambda x_{3} x_{4}
\end{aligned}
$$

where

$$
\begin{aligned}
\alpha & =\frac{1}{2} m \omega^{2}-\lambda \cos \varphi \sin \varphi \\
\beta & =\frac{1}{2} m \omega^{2}+\lambda \cos \varphi \sin \varphi \\
\gamma & =\lambda \cos 2 \varphi \\
\mu & =\lambda \cos \varphi \\
v & =\lambda \sin \varphi
\end{aligned}
$$

To eliminate the system-system coupling, $\gamma$ must vanish which is effective when the condition, $\varphi=\frac{(2 n+1) \pi}{4}$, with $n=0,1,2, \ldots$, is imposed thereby obtaining a newly defined Lagrangian written in Equation (21).

$$
\begin{aligned}
L= & \frac{1}{2} m\left(\dot{q}_{1}^{2}+\dot{q}_{2}^{2}+\dot{x}_{3}^{2}+\dot{x}_{4}^{2}\right)-\frac{1}{2} m \Omega_{1}^{2} q_{1}^{2} \\
& -\frac{1}{2} m \Omega_{2}^{2} q_{2}^{2}-\frac{1}{2} m \omega_{3}^{2} q_{3}^{2}-\frac{1}{2} m \omega_{4}^{2} q_{4}^{2} \\
& +\frac{\sqrt{2}}{2} q_{1} x_{3}-\frac{\sqrt{2}}{2} q_{2} x_{3}-\frac{\sqrt{2}}{2} q_{1} x_{4} \\
& -\frac{\sqrt{2}}{2} q_{2} x_{4}-\lambda x_{3} x_{4}
\end{aligned}
$$

where the new frequencies are defined as $\Omega_{1}^{2}=\omega^{2}-\frac{\lambda}{m} \quad$ and $\quad \Omega_{2}^{2}=\omega^{2}+\frac{\lambda}{m} . \quad$ The Lagrangian in Equation (21) seems unlikely for another set of coupling arise, however, the situation can be handled by decoupling the original coordinates left through the coordinate transformation given by the relations in Equations (22) and (23).

$$
\begin{aligned}
& x_{3}=q_{3} \cos \theta+q_{4} \sin \theta \\
& x_{4}=-q_{3} \sin \theta+q_{4} \cos \theta
\end{aligned}
$$

Differentiating Equations (22) and (23) and substitute into Equation (21) yields the new Lagrangian given by Equation (24).

$$
\begin{aligned}
L= & \frac{1}{2} m\left(\dot{q}_{1}^{2}+\dot{q}_{2}^{2}+\dot{q}_{3}^{2}+\dot{q}_{4}^{2}\right)-\frac{1}{2} m \Omega_{1}^{2} q_{1}^{2} \\
- & \frac{1}{2} m \Omega_{2}^{2} q_{2}^{2}-A q_{3}^{2}-B q_{4}^{2}+C q_{1} q_{3} \\
& -C q_{2} q_{4}-D q_{3} q_{4}
\end{aligned}
$$

where

$$
\begin{aligned}
& A=\frac{1}{2} m \Omega_{3}^{2}-\lambda \cos \theta \sin \theta \\
& B=\frac{1}{2} m \Omega_{4}^{2}+\lambda \cos \theta \sin \theta \\
& C=\frac{\sqrt{2} \lambda}{2}(\cos \theta+\sin \theta) \\
& D=\lambda \cos 2 \theta
\end{aligned}
$$

Furthermore, variable $D$ must vanish by imposing the condition $\theta=\frac{(2 n+1) \pi}{4}$, with $n=0,1,2, \ldots$. Simplifying the Equations yield given by Equation (29). 


$$
\begin{aligned}
L= & \frac{1}{2} m\left(\dot{q}_{1}^{2}+\dot{q}_{2}^{2}+\dot{q}_{3}^{2}+\dot{q}_{4}^{2}\right)-\frac{1}{2} m \Omega_{1}^{2} q_{1}^{2} \\
& -\frac{1}{2} m \Omega_{2}^{2} q_{2}^{2}-\frac{1}{2} m \Omega_{3}^{2} q_{3}^{2}-\frac{1}{2} m \Omega_{4}^{2} q_{4}^{2} \\
& +\lambda q_{1} q_{3}-\lambda q_{2} q_{4}
\end{aligned}
$$

with the frequencies written as $\Omega_{3}^{2}=\omega^{2}-\frac{\lambda}{m}$ and $\Omega_{4}^{2}=\omega^{2}+\frac{\lambda}{m}$. Notice in Equation (29), there are only two couplings left and by decoupling the coordinates further using the relations in Equations (30) and (31).

$$
\begin{gathered}
q_{1}=Q_{1} \cos \phi+Q_{3} \sin \phi \\
q_{3}=-Q_{1} \sin \phi+Q_{3} \cos \phi
\end{gathered}
$$

yields the new Lagrangian written in Equation (32).

$$
\begin{aligned}
L= & \frac{1}{2} m\left(\dot{Q}_{1}^{2}+\dot{q}_{2}^{2}+\dot{Q}_{3}^{2}+\dot{q}_{4}^{2}\right)-\frac{1}{2} m \Phi_{1}^{2} Q_{1}^{2} \\
& -\frac{1}{2} m \Omega_{2}^{2} q_{2}^{2}-\frac{1}{2} m \Phi_{3}^{2} Q_{3}^{2}-\frac{1}{2} m \Omega_{4}^{2} q_{4}^{2} \\
& -\lambda q_{2} q_{4}
\end{aligned}
$$

Lastly, the transformation for coordinates $q_{2}$ and $q_{4}$ is performed with Equations (33) and (34).

$$
\begin{gathered}
q_{2}=Q_{2} \cos \vartheta+Q_{4} \sin \vartheta \\
q_{4}=-Q_{2} \sin \vartheta+Q_{4} \cos \vartheta
\end{gathered}
$$

and simplification now gives a separable Lagrangian of the form:

$$
\begin{aligned}
& L_{1}=\frac{1}{2} m \dot{Q}_{1}^{2}-\frac{1}{2} m \Phi_{1}^{2} Q_{1}^{2} \\
& L_{2}=\frac{1}{2} m \dot{Q}_{2}^{2}-\frac{1}{2} m \Phi_{2}^{2} Q_{2}^{2} \\
& L_{3}=\frac{1}{2} m \dot{Q}_{3}^{2}-\frac{1}{2} m \Phi_{3}^{2} Q_{3}^{2} \\
& L_{4}=\frac{1}{2} m \dot{Q}_{4}^{2}-\frac{1}{2} m \Phi_{4}^{2} Q_{4}^{2}
\end{aligned}
$$

where the newly defined frequencies are $\Phi_{1}=\omega, \quad \Phi_{2}=\omega, \quad \Phi_{3}=\sqrt{\omega^{2}-(2 \lambda / m)}$, and $\Phi_{4}=\sqrt{\omega^{2}+(2 \lambda / m)}$. Evidently, the total Lagrangian is seen to be separable into propagators of four independent harmonic oscillators which can now be evaluated with more ease. Moreover, the classical action in Equation (6) can be written as $S=S_{1}+S_{2}+S_{3}+S_{4}$, with the value $S_{i}=\int_{0}^{t} L_{i} d \tau$, where $i=1,2,3,4$. The full propagator is written as $K\left(Q_{1}, Q_{2}, Q_{3}, Q_{4}, Q_{1 o}, Q_{2 o}, Q_{3 o}, Q_{4 o} ; \tau\right)=$ $K\left(Q_{1}, Q_{1 o} ; \tau\right) K\left(Q_{2}, Q_{2 o} ; \tau\right) K\left(Q_{3}, Q_{3 o} ; \tau\right) \times$ $K\left(Q_{4}, Q_{4 o} ; \tau\right)$, where

$$
\begin{aligned}
& K\left(Q_{1}, Q_{1 o} ; \tau\right)=K_{Q_{1}}=\int \exp \left(\frac{i}{\hbar} S_{1}\right) D\left[Q_{1}\right] \\
& K\left(Q_{2}, Q_{2 o} ; \tau\right)=K_{Q_{2}}=\int \exp \left(\frac{i}{\hbar} S_{2}\right) D\left[Q_{2}\right] \\
& K\left(Q_{3}, Q_{3 o} ; \tau\right)=K_{Q_{3}}=\int \exp \left(\frac{i}{\hbar} S_{3}\right) D\left[Q_{3}\right] \\
& K\left(Q_{4}, Q_{4 o} ; \tau\right)=K_{Q_{4}}=\int \exp \left(\frac{i}{\hbar} S_{4}\right) D\left[Q_{4}\right]
\end{aligned}
$$

The next step is to evaluate the individual propagators using the path integral in the language of white noise analysis.

\section{The Evaluation of $K_{Q_{1}}$}

Using the evaluation of the propagator in Equation (11), the classical action $S_{1}=\int L_{1} d \tau$ can be substituted yielding in Equation (43).

$$
\begin{aligned}
& K_{Q_{1}}=N \int \exp \left[\frac{i+1}{2} \int_{0}^{t} \omega(\tau)^{2} d \tau\right] \\
& \times \exp \left[-\frac{i}{\hbar} \int_{0}^{t} S_{V}\left(Q_{1}\right) d \tau\right] \delta\left(x(t)-x_{1}\right) d \mu(\omega)
\end{aligned}
$$

where $S_{V}\left(Q_{1}\right)$ is the effective action for the harmonic oscillator potential. The form of parametrization in Equation (7) is used and is substituted into the Donsker delta function in Equation (10) as follows in Equation (44). 


$$
\begin{aligned}
\delta\left(x(t)-x_{1}\right) & =\frac{1}{2 \pi} \int_{-\infty}^{\infty} \exp \left[i \lambda\left(Q_{1 o}-Q_{1}\right)\right] \\
& \times \exp \left[i \lambda \int_{0}^{t} \omega(\tau) d \tau\right] d \lambda
\end{aligned}
$$

The second exponential expression containing the potential in Equation (43) is then parametrized yielding to $\exp \left[-\frac{i}{\hbar} \int_{0}^{t} \frac{1}{2} m \Phi_{1}^{2}\left(Q_{1 o}+\int_{0}^{t} \omega(\tau) d \tau\right)^{2}\right]$.

This expression is found to be second degree in white noise and to make it easier to deal with, the Taylor series expansion [25] is used, that in Equation (45).

$$
\begin{gathered}
S_{V}\left(Q_{1}\right) \approx S_{V}\left(Q_{1 o}\right)+\frac{1}{1 !} \int d \tau \omega(\tau) \frac{\partial S_{V}\left(Q_{1 o}\right)}{\partial \omega(\tau)} \\
+\frac{1}{2 !} \int d \tau_{1} d \tau_{2} \omega\left(\tau_{1}\right) \frac{\partial^{2} S_{V}\left(Q_{1 o}\right)}{\partial \omega\left(\tau_{1}\right) \partial \omega\left(\tau_{2}\right)} \omega\left(\tau_{1}\right)
\end{gathered}
$$

Choosing the initial point $Q_{10}=0$ leads to $S_{V}\left(Q_{1 o}\right)=0$ and Equation (46) and (47).

$$
\begin{aligned}
S^{\prime} & =\frac{\partial S_{V}(0)}{\partial \omega(\tau)}=\frac{\hbar}{m} \int V^{\prime}(0) d \tau \Rightarrow 0 \\
S^{\prime \prime} & =\frac{\partial^{2} S_{V}(0)}{\partial \omega\left(\tau_{1}\right) \partial \omega\left(\tau_{2}\right)}=\frac{\hbar}{m} \int_{\tau_{1} \vee \tau_{2}}^{t} V^{\prime \prime}(0) d \tau \\
& \Rightarrow \hbar \Phi_{1}^{2}\left(t-\tau_{1} \vee \tau_{2}\right)
\end{aligned}
$$

Utilizing Equations (44), (46), and (47) transforms the propagator into Equation (48).

$$
K_{Q_{1}}=\int_{-\infty}^{\infty} \frac{\exp \left[-i \lambda Q_{1}\right]}{2 \pi}\left[T . I .\left(\sqrt{\frac{\hbar}{m}} \lambda\right)\right] d \lambda
$$

where $I$ is the white noise functional given by Equation (49).

$$
\begin{gathered}
I=N \exp \left[-\frac{1}{2}\langle\omega,-(i+1) \omega\rangle\right] \\
\times \exp \left[-\frac{1}{2}\left\langle\omega, \frac{i}{\hbar} S^{\prime \prime} \omega\right\rangle\right]
\end{gathered}
$$

with the notation $\langle$,$\rangle as an integral over d \tau$.

The evaluation of the Feynman path integral is carried by the $T$-transform given by Equation (50).

$$
\begin{aligned}
\operatorname{T.I.}(\xi & =\sqrt{\hbar / m} \lambda) \\
& =\int \operatorname{Iexp}[i\langle\omega, \sqrt{\hbar / m} \lambda\rangle] d \mu(\omega)
\end{aligned}
$$

which can be simplified to Equation (51).

$$
\begin{aligned}
& T . I=\left[\operatorname{det}\left(1+L(K+1)^{-1}\right)\right]^{-\frac{1}{2}} \\
& \times \exp \left[-\frac{1}{2}(K+L+1)^{-1} \int_{0}^{t}\left(\sqrt{\frac{\hbar}{m}} \lambda\right)^{2} d \tau\right]
\end{aligned}
$$

where $K=-(i+1)$ and $L=i \hbar^{-1} S^{\prime \prime}$. Substituting Equation (50) into Equation (48) yields in Equation (52).

$$
\begin{aligned}
K_{Q_{1}} & =\frac{1}{2 \pi}\left[\operatorname{det}\left(1-\hbar^{-1} S^{\prime \prime}\right)\right]^{\frac{1}{2}} \\
& \times \int_{-\infty}^{\infty} d \lambda \exp \left[\frac{-i \hbar t\left(1-\hbar^{-1} S^{\prime \prime}\right)^{-1}}{2 m} \lambda^{2}-i Q_{1} \lambda\right]
\end{aligned}
$$

The kernel in Equation (52) obeys the Gaussian integration over the variable $\lambda$ which gives the expression in Equation (53).

$$
\begin{aligned}
K_{Q_{1}} & =\frac{1}{2 \pi}\left[\operatorname{det}\left(1-\hbar^{-1} S^{\prime \prime}\right)\right]^{\frac{1}{2}} \\
& \times \sqrt{\frac{2 \pi m}{i \hbar t\left\langle e,\left(i \hbar^{-1} S^{\prime \prime}\right) e\right\rangle}} \exp \left[\frac{i m Q_{1}^{2}}{2 \hbar t\left\langle e,\left(i \hbar^{-1} S^{\prime \prime}\right) e\right\rangle}\right]
\end{aligned}
$$

with the unit vector defined as $e=t^{-\frac{1}{2}} \chi_{[0, t]}$. Further simplification [31] yields in Equation (54) and (55).

$$
\begin{aligned}
& \operatorname{det}\left(1-\hbar^{-1} S^{\prime \prime}\right)=\cos \Phi_{1} t \\
& \left\langle e,\left(i \hbar^{-1} S^{\prime \prime}\right) e\right\rangle=\frac{1}{\Phi_{1} t} \tan \Phi_{1} t
\end{aligned}
$$

Finally, employing Equations (54) and (55) to Equation (53) gives the $Q_{1}-$ dimension propagator into Equation (56).

$$
K_{Q_{1}}=\sqrt{\frac{m \Phi_{1}}{2 \pi i \hbar t \sin \Phi_{1} t}} \exp \left[\frac{i m \Phi_{1}}{2 \hbar} Q_{1}^{2} \cot \Phi_{1} t\right]
$$


Propagators of $K_{Q_{2}}, K_{Q_{3}}$ and $K_{Q_{4}}$

Notice that the Lagrangians $L_{2}, L_{3}$ and $L_{4}$ are just the same with that of Lagrangian $L_{1}$. Thus, by following the same procedure of evaluation in $Q_{1}$-dimension, we obtain the propagators in Equation (57), (58), and (59).

$K_{Q_{2}}=\sqrt{\frac{m \Phi_{2}}{2 \pi i \hbar t \sin \Phi_{2} t}} \exp \left[\frac{i m \Phi_{2}}{2 \hbar} Q_{2}^{2} \cot \Phi_{2} t\right]$

$K_{Q_{3}}=\sqrt{\frac{m \Phi_{3}}{2 \pi i \hbar t \sin \Phi_{3} t}} \exp \left[\frac{i m \Phi_{3}}{2 \hbar} Q_{3}^{2} \cot \Phi_{3} t\right]$

$K_{Q_{4}}=\sqrt{\frac{m \Phi_{4}}{2 \pi i \hbar t \sin \Phi_{4} t}} \exp \left[\frac{i m \Phi_{4}}{2 \hbar} Q_{4}^{2} \cot \Phi_{4} t\right]$

The total propagator of the system can now be evaluated.

\section{Full Propagator}

The full propagator for the system is just the product of the individual propagators. For a four-coupled system, the Feynman quantum propagator is given by Equation (60).

$$
\begin{aligned}
& K\left(x_{1}, x_{2}, x_{3}, x_{4}, x_{1 o}, x_{2 o}, x_{3 o}, x_{4 o} ; \tau\right)=\int D x_{1} \\
& \times D x_{2} D x_{3} D x_{4} \exp \left[\frac{i}{\hbar}\left(S_{1}+S_{2}+S_{3}+S_{4}\right)\right]
\end{aligned}
$$

where $D x_{1}, D x_{2}, D x_{3}$, and $D x_{4}$ are the functional measures. Notice from Equation (60) that it is a product of four functional measures given by Equation (61).

$$
D x_{1} D x_{2} D x_{3} D x_{4}=J D Q_{1} D Q_{2} D Q_{3} D Q_{4} \text { (61) }
$$

where $J$ is the Jacobian for the transformation. Since the system we deal with is of equal masses, Equation (61) is rewritten in Equation (62).

$$
D x_{1} D x_{2} D x_{3} D x_{4}=D Q_{1} D Q_{2} D Q_{3} D Q_{4}
$$

making the propagator in Equation (63).

$$
\begin{aligned}
& K\left(Q_{1}, Q_{2}, Q_{3}, Q_{4}, Q_{1 o}, Q_{2 o}, Q_{3 o}, Q_{4 o} ; \tau\right) \\
& =K\left(Q_{1}, Q_{1 o} ; \tau\right) K\left(Q_{2}, Q_{2 o} ; \tau\right) K\left(Q_{3}, Q_{3 o} ; \tau\right) \\
& \quad \times K\left(Q_{4}, Q_{4 o} ; \tau\right)
\end{aligned}
$$

In determining the full propagator, each coordinate must be transformed to its original form, and by doing so, the following relationships are obtained in Equation (64) and (65).

$$
\begin{aligned}
& Q_{1}=q_{1} \cos \phi-q_{3} \sin \phi \\
& Q_{3}=q_{1} \sin \phi+q_{3} \cos \phi
\end{aligned}
$$

The expressions in Equations (64) and (65) being substituted in Equations (56) and (58) respectively, yields Equation (66) and (67).

$$
\begin{aligned}
K_{Q_{1}} & =\sqrt{\frac{m \Phi_{1}}{2 \pi i \hbar t \sin \Phi_{1} t}} \\
& \times \exp \left[\frac{i m \Phi_{1}}{2 \hbar}\left(q_{1}-q_{3}\right)^{2} \cot \Phi_{1} t\right] \\
K_{Q_{3}} & =\sqrt{\frac{m \Phi_{3}}{2 \pi i \hbar t \sin \Phi_{3} t}} \\
& \times \exp \left[\frac{i m \Phi_{3}}{2 \hbar}\left(q_{1}+q_{3}\right)^{2} \cot \Phi_{3} t\right]
\end{aligned}
$$

Using the same method utilized above through the relations in Equations (68) and (69).

$$
\begin{aligned}
& Q_{2}=q_{2} \cos \vartheta-q_{4} \sin \vartheta \\
& Q_{4}=q_{2} \sin \vartheta+q_{4} \cos \vartheta
\end{aligned}
$$

Yields Equation (70) and (71).

$$
\begin{aligned}
K_{Q_{2}} & =\sqrt{\frac{m \Phi_{2}}{2 \pi i \hbar t \sin \Phi_{2} t}} \\
& \times \exp \left[\frac{i m \Phi_{2}}{2 \hbar}\left(q_{2}-q_{4}\right)^{2} \cot \Phi_{2} t\right] \\
K_{Q_{4}} & =\sqrt{\frac{m \Phi_{4}}{2 \pi i \hbar t \sin \Phi_{4} t}} \\
& \times \exp \left[\frac{i m \Phi_{4}}{2 \hbar}\left(q_{2}+q_{4}\right)^{2} \cot \Phi_{4} t\right]
\end{aligned}
$$

Finally, transforming the $q_{1}, q_{2}, q_{3}$, and $q_{4}$ coordinates into $x_{1}, x_{2}, x_{3}$, and $x_{4}$, coordinates give us the expression for the full propagator of the system in Equation (72). 


$$
\begin{aligned}
K_{F}= & \left(\frac{m}{2 \pi i \hbar t}\right)^{2} \\
\times & \left.\times \frac{\Phi_{1} \Phi_{2} \Phi_{3} \Phi_{4}}{\sin \Phi_{1} t \sin \Phi_{2} t \sin \Phi_{3} t \sin \Phi_{4} t}\right]^{\frac{1}{2}} \\
\times & \exp \left[\frac{i m \Phi_{1}}{4 \hbar}\left[\frac{\sqrt{2}}{2}\left(x_{1}-x_{2}-x_{3}+x_{4}\right)\right]^{2}\right. \\
\times & \left.\times \cot \Phi_{1} t\right] \\
\times & \quad \times \exp \left[\frac{i m \Phi_{2}}{4 \hbar}\left[\frac{\sqrt{2}}{2}\left(x_{1}+x_{2}-x_{3}-x_{4}\right)\right]^{2}\right. \\
& \quad \times \cot t] \\
\times & \exp \left[\frac{\sqrt{2}}{2}\left(x_{1}-x_{2}+x_{3}-x_{4}\right)\right]^{2} \\
& \left.\quad \times \cot \Phi_{4} t\right]
\end{aligned}
$$

\section{The Wave Function and Energy Spectrum}

From the result in Equation (72), the propagator can be expressed in Equation (73). $K\left(x_{1}, x_{2}, x_{3}, x_{4}, 0,0,0,0 ; \tau\right)$

$$
\begin{aligned}
& =\sum_{n_{1}, n_{2}, n_{3}, n_{4} \in N} \Psi_{n_{1}, n_{2}, n_{3}, n_{4}}^{*}\left(x_{1}, x_{2}, x_{3}, x_{4}\right) \\
& \times \Psi_{n_{1}, n_{2}, n_{3}, n_{4}}(0,0,0,0) e^{-\frac{i}{\hbar} t E n_{1}, n_{2}, n_{3}, n_{4}}
\end{aligned}
$$

for an initial point $x_{1 o}=x_{2 o}=x_{3 o}=x_{4 o}=0$. Using the relations in Equations (74) and (75).

$$
\begin{gathered}
i \sin \Phi t=\frac{1}{2} e^{i \Phi t}\left(1-e^{-2 i \Phi t}\right) \\
\cos \Phi t=\frac{1}{2} e^{i \Phi t}\left(1+e^{-2 i \Phi t}\right)
\end{gathered}
$$

and the Mehler formula [27] of the form in Equation (76).

$$
\begin{aligned}
& \frac{1}{\sqrt{1-z^{2}}} \exp \left[\frac{4 x y z-\left(x^{2}+y^{2}\right)\left(1+z^{2}\right)}{2\left(1-z^{2}\right)}\right] \\
& =e^{-\frac{\left(x^{2}+y^{2}\right)}{2}} \sum_{n=0}^{\infty} \frac{1}{n !}\left(\frac{z}{2}\right)^{n} H_{n}(x) H_{n}(y)
\end{aligned}
$$

where the functions $H_{n}$ are the Hermite polynomials given by Equation (77).

$$
H_{n}(y)=(-1)^{n} e^{y^{2}} \frac{d^{n}}{d y^{n}} e^{-y^{2}}
$$

the propagator can be written in its symmetric form in Equation (78).

$$
\begin{aligned}
& K\left(x_{1}, x_{2}, x_{3}, x_{4}, 0,0,0,0 ; \tau\right) \\
& =\frac{1}{\sqrt{2}}\left(\frac{m}{\pi \hbar t}\right)^{2}\left(\Phi_{1} \Phi_{2} \Phi_{3} \Phi_{4}\right)^{\frac{1}{2}} \\
& \quad \times \exp \left\{-\frac{m}{4 \hbar}\left[\Phi_{1}\left[\frac{\sqrt{2}}{2}\left(x_{1}-x_{2}-x_{3}+x_{4}\right)\right]^{2}\right.\right. \\
& \quad+\Phi_{2}\left[\frac{\sqrt{2}}{2}\left(x_{1}+x_{2}-x_{3}-x_{4}\right)\right]^{2} \\
& \quad+\Phi_{3}\left[\frac{\sqrt{2}}{2}\left(x_{1}-x_{2}+x_{3}-x_{4}\right)\right]^{2} \\
& \left.\left.\quad+\Phi_{4}\left[\frac{\sqrt{2}}{2}\left(x_{1}+x_{2}+x_{3}+x_{4}\right)\right]^{2}\right]\right\} \\
& \quad \sum_{n_{1}, n_{2}, n_{3}, n_{4} \epsilon N}\left(2^{n_{1}} n_{1} !\right)^{-1}\left(2^{n_{2}} n_{2} !\right)^{-1}\left(2^{n_{3}} n_{3} !\right)^{-1} \\
& \quad \times\left(2^{n_{4}} n_{4} !\right)^{-1} \exp \left\{-i t\left[\frac { 1 } { 2 } \left(\Phi_{1}+\Phi_{2}+\Phi_{3}\right.\right.\right. \\
& \left.\left.\left.\quad+\Phi_{4}\right)+n_{1} \Phi_{1}+n_{2} \Phi_{2}+n_{3} \Phi_{3}+n_{4} \Phi_{4}\right]\right\} \\
& \times H_{n_{1}}\left(\sqrt{\frac{m \Phi_{1}}{2 \hbar}}\left[\frac{\sqrt{2}}{2}\left(x_{1}-x_{2}-x_{3}+x_{4}\right)\right]\right) \\
& \times H_{n_{3}}\left(\sqrt{\frac{m \Phi_{3}}{2 \hbar}}\left[\frac{\sqrt{2}}{2}\left(x_{1}-x_{2}+x_{3}-x_{4}\right)\right]\right) \\
& \times H_{n_{2}}\left(\sqrt{\frac{m \Phi_{2}}{2 \hbar}}\left[\frac{\sqrt{2}}{2}\left(x_{1}+x_{2}-x_{3}-x_{4}\right)\right]\right)
\end{aligned}
$$$$
\times H_{n_{4}}\left(\sqrt{\frac{m \Phi_{4}}{2 \hbar}}\left[\frac{\sqrt{2}}{2}\left(x_{1}+x_{2}+x_{3}+x_{4}\right)\right]\right)
$$

From this, the energy spectrum is extracted giving in Equation (79).

$$
\begin{gathered}
E_{n_{1}, n_{2}, n_{3}, n_{4}}=\hbar\left[\left(n_{1}+\frac{1}{2}\right) \Phi_{1}+\left(n_{2}+\frac{1}{2}\right) \Phi_{2}\right. \\
\left.+\left(n_{3}+\frac{1}{2}\right) \Phi_{3}+\left(n_{4}+\frac{1}{2}\right) \Phi_{4}\right]
\end{gathered}
$$

and the general formula for the wave function in Equation (80). 


$$
\begin{aligned}
& \Psi_{n_{1}, n_{2}, n_{3}, n_{4}} \\
& =\frac{m}{\pi \hbar t} \sqrt{\frac{\sqrt{\Phi_{1} \Phi_{2} \Phi_{3} \Phi_{4}}}{(\sqrt{2})\left(2^{\left(n_{1}+n_{2}+n_{3}+n_{4}\right)} n_{1} ! n_{2} ! n_{3} ! n_{4} !\right)}} \\
& \times \exp \left\{-\frac{m}{4 \hbar}\left[\Phi_{1}\left[\frac{\sqrt{2}}{2}\left(x_{1}-x_{2}-x_{3}+x_{4}\right)\right]^{2}\right.\right. \\
& +\Phi_{2}\left[\frac{\sqrt{2}}{2}\left(x_{1}+x_{2}-x_{3}-x_{4}\right)\right]^{2} \\
& +\Phi_{3}\left[\frac{\sqrt{2}}{2}\left(x_{1}-x_{2}+x_{3}-x_{4}\right)\right]^{2} \\
& \left.\left.+\Phi_{4}\left[\frac{\sqrt{2}}{2}\left(x_{1}+x_{2}+x_{3}+x_{4}\right)\right]^{2}\right]\right\} \\
& \times H_{n_{1}}\left(\sqrt{\frac{m \Phi_{1}}{2 \hbar}}\left[\frac{\sqrt{2}}{2}\left(x_{1}-x_{2}-x_{3}+x_{4}\right)\right]\right) \\
& \times H_{n_{2}}\left(\sqrt{\frac{m \Phi_{2}}{2 \hbar}}\left[\frac{\sqrt{2}}{2}\left(x_{1}+x_{2}-x_{3}-x_{4}\right)\right]\right) \\
& \times H_{n_{3}}\left(\sqrt{\frac{m \Phi_{3}}{2 \hbar}}\left[\frac{\sqrt{2}}{2}\left(x_{1}-x_{2}+x_{3}-x_{4}\right)\right]\right) \\
& \times H_{n_{4}}\left(\sqrt{\frac{m \Phi_{4}}{2 \hbar}}\left[\frac{\sqrt{2}}{2}\left(x_{1}+x_{2}+x_{3}+x_{4}\right)\right]\right)
\end{aligned}
$$

This result agrees with the particular case dealt by $[14-16,18]$ when the third and fourth coordinates are set to zero and de Souza Dutra [17] for the non-driven case (when $f_{1}$ and $f_{2}$ of Equation (32) are set to zero). In contrast, the works of Hong-Yi [9-10] contain cross-coupling constants of inter-particle harmonic oscillator forces, which in turn, gives a different form of wave functions.

One remarkable feature of the quantization for this system is the appearance of the energy spectrum to be degenerate provided that the frequencies $\Phi_{1}, \Phi_{2}, \Phi_{3}$, and $\Phi_{4}$ are related conveniently. Also, the four-coupled system is usually applied to a rotationally invariant system where symmetric characteristic and synchronization is important in many concepts of quantum mechanics. Finally, when the four-coupled oscillator is extended into $N$ coupled oscillators interacting with a system, it can be used in modeling energy transport in solidstate and biological systems [20]. For the case of a harmonic oscillator system interacting with the $\mathrm{N}$ coupled oscillator environment, the resulting dynamics is vital to the comprehension of dissipation in quantum computing [43].

\section{CONCLUSION}

The quantum propagator for the ring of four harmonically coupled oscillators has been derived successfully through white noise analysis. After decoupling and evaluating the full Lagrangian, it is observed that it was just the product of the four propagators. The decoupled system showed the differences in normal mode frequencies: the first and second propagators showed degeneracy while the other two exhibited non-degeneracy. Moreover, the propagator was expressed in its symmetric form wherein the energy spectrum was just the sum of the energies of the four harmonic oscillators.

The results in this work indeed, prove the promise of white noise analysis in analyzing systems of many degrees of freedom. In addition, the authors will explore the areas where there are systems of $N$-coupled oscillators in future works. The said system, when coupled to an environment, can be used to model quantum transport of energy excitation in solid-state and biological systems.

\section{ACKNOWLEDGMENT}

The authors are grateful to Central Mindanao University for the conducive environment for theoretical learning especially in the field of physics. 
Jurnal Penelitian Fisika dan Aplikasinya (JPFA), 2019; 9(2): 92-104

\section{REFERENCES}

[1] Brown KR, Ospelkaus C, Colombe Y, Wilson AC, Leibfried D, and Wineland DJ. Coupled Quantized Mechanical Oscillators. Nature. 2011; 471: 196-199. DOI:

https://doi.org/10.1038/nature09721.

[2] Makarov DN. Coupled Harmonic Oscillators and Their Quantum Entanglement. Physical Review E. 2018; 97: 042203. DOI: https://doi.org/10.1103/PhysRevE.97.04220 3.

[3] Chakraborty S and Sarma AK. Entanglement Dynamics of Two Coupled Mechanical Oscillators in Modulated Optomechanics. Physical Review A. 2018; 97: 022336. DOI: https://doi.org/10.1103/PhysRevA.97.02233 6.

[4] Delor M, Archer SA, Keane T, Meijer AJHM, Sazanvich IV, Greetham GM, Towrie M, and Weinstein JA. Directing the Path of LightInduced Electron Transfer at a Molecular Fork using Vibrational Excitation. Nature Chemistry. 2017; 9: 1099-1104. DOI: https://doi.org/10.1038/nchem.2793.

[5] Sasihithlu K. A Coupled Harmonic Oscillator Model to Describe the Near-Field Radiative Heat Transfer Between Nanoparticles and Planar Surfaces; 2018. Available from: https://arxiv.org/abs/1810.02548.

[6] Romero E, Augulis A, Novoderezhkin VI, Ferritti M, Thieme J, Zigmantas D, and van Grondelle R. Quantum Coherence in Photosynthesis for Efficient Solar-Energy Conversion. Nature Physics. 2014; 10: 676-682. DOI:

https://doi.org/10.1038/nphys3017.

[7] Fuller FD, Pan J, Gelzinis A, Butkus V, Senlik S, Wilcox DE, Yocum CF, Valkunas L, Abravicius D and Ogilvie JP. Vibrionic Coherence in Oxygenic Photosynthesis. Nature Chemistry. 2014; 6: 706-711. DOI: https://doi.org/10.1038/nchem.2005.
[8] Bhattacharya M and Shi H. Coupled SecondQuantized Oscillators. American Journal of Physics. 2013; 81: 267-273. DOI: https://doi.org/10.1119/1.4792696.

[9] Hong-Yi F. New Unitary Transformation for The Three Coupled Oscillators. International Journal of Quantum Chemistry. 1989; 35(5): 585-592. DOI:

https://doi.org/10.1002/qua.560350502.

[10] Hong-Yi F. Unitary Transformation of Four Harmonically Coupled Identical Oscillators. Physical Review A. 1990; 42: 4337. DOI: https://doi.org/10.1103/PhysRevA.42.4377.

[11] Zuniga J, Bastid A, and Requena A. Quantum Solution of Coupled Harmonic Oscillator Systems Beyond Normal Coordinates. Journal of Mathematical Chemistry. 2017; 55(10): 1964-1984. DOI:

https://doi.org/10.1007/s10910-017-07771 .

[12] Dolfo G and Vigue J. Damping of Coupled Harmonic Oscillators. European Journal of Physics. 2018; 39(2): 025005. DOI: https://doi.org/10.1088/1361-6404/aa9ec6.

[13] Rodriguez SRK. Classical and Quantum Distinctions Between Weak and Strong Coupling. European Journal of Physics. 2016; 37(2): 025802. DOI:

https://doi.org/10.1088/01430807/37/2/025802.

[14] Macedo DX and Guedes I. Time-Dependent Coupled Harmonic Oscillators: Classical and Quantum Solutions. International Journal of Modern Physics E. 2014; 23(09): 1450048. DOI:

https://doi.org/10.1142/S0218301314500487.

[15] Macedo DX and Guedes I. Time-dependent coupled harmonic oscillators. Journal of Mathematical Physics. 2012; 53: 052101. DOI: https://doi.org/10.1063/1.4709748.

[16] McDermott RM and Redmount RH. Coupled Classical and Quantum Oscillators; 2004. 
Jurnal Penelitian Fisika dan Aplikasinya (JPFA), 2019; 9(2): 92-104

Available from: https://arxiv.org/abs/quant$\mathrm{ph} / 0403184$.

[17] Dutra ADS. On the Quantum Mechanical Propagator for Driven Coupled Harmonic Oscillators. Journal of Physics A: Mathematical and General. 1992; 25(15), 4189. DOI: https://doi.org/10.1088/0305$\underline{4470 / 25 / 15 / 026}$.

[18] Pabalay JR and Bornales JB. Coupled Harmonic Oscillators: A White Noise Functional Approach. Undergraduate Thesis. Unpublished. Iligan: Iligan Institute of Technology Mindanao State University; 2007.

[19] Butanas-Jr BM and Caballar RCF. Coupled Harmonic Oscillator in A Multimode Harmonic Oscillator Bath: Derivation of Quantum Propagator and Master Equation Using White Noise Analysis; 2016. Available from: https://arxiv.org/abs/1607.01906.

[20] Butanas-Jr BM and Caballar RCF. Quantum Propagator Dynamics of a Harmonic Oscillator in a Multimode Harmonic Oscillators Environment using White Noise Functional Analysis; 2017. Available from: https://arxiv.org/pdf/1703.04909.

[21] Feynman RP. Space-Time Approach to NonRelativistic Quantum Mechanics. Reviews of Modern Physics. 1948; 20(2):367-387. DOI: https://doi.org/10.1103/RevModPhys.20.367.

[22] Bernido CC and Bernido MVC. White Noise Analysis: Some Applications in Complex Systems, Biophysics and Quantum Mechanics. International Journal of Modern Physics B. 2012; 26(29): 1230014. DOI: https://doi.org/10.1142/S02179792123 $\underline{00149}$.

[23] Bernido CC and Bernido MVC. Methods and Application of White Noise Analysis in Interdisciplinary Sciences; 2015. DOI: https://doi.org/10.1142/9789814569125 000 6.

[24] Bock W and Grothaus M. A White Noise
Approach to Phase Space Feynman Path Integrals; 2010. Available from: http://arxiv.org/abs/1012.1125v1.

[25] Streit L and Hida T. Generalized Brownian Functionals and the Feynman Integral. Stochastic Processes and their Applications. 1984; 16(1): 55-69. DOI:

https://doi.org/10.1016/03044149(84)90175-3.

[26] Butanas BM and Esguerra JP. White Noise Functional Approach to the Brownian Motion of the Free Particle. Proceedings of the Samahang Pisika ng Pilipinas 36. 2018. Available from: https://paperview.spponline.org/proceedings/article/view/SPP2018-PB-03.

[27] Butanas BM and Caballar RCF. On the Derivation of Nakajima-Zwanzig Probability Density Function Via White Noise Analysis. AIP Conference Proceedings. 2017; 1871: 020006. DOI:

https://doi.org/10.1063/1.4996516.

[28] Butanas BM and Caballar RCF. Normal Mode Propagator Dynamics of a Double Harmonic Oscillator in an Environment Using White Noise Analysis. Proceedings of the Samahang Pisika ng Pilipinas 35. 2017. Available from: https://paperview.spponline.org/proceedings/article/view/110.

[29] Baybayon RN, Bornales JB, and Cubero RJ. A Hida-Streit Formulation Approach in Evaluating the Quantum Mechanical Propagator of a Particle Moving in a Constant Force Field with Constant Friction. Proceedings of the $12^{\text {th }}$ SPVM National Physics Conference. 2019. Available from: https://www.researchgate.net/publication/33 0467899 A Hida-

Streit_Formulation_Approach_in_Evaluatin g the Quantum Mechancal Propagator of a_Particle_Moving_in_aConstant_Force_fi eld with Constant Friction. 
Jurnal Penelitian Fisika dan Aplikasinya (JPFA), 2019; 9(2): 92-104

[30] Butanas BM and Caballar RCF. The Caldeira-Leggett Model in A Harmonic Potential: Derivation of Master Equation and Quantum Propagator Through A White Noise Functional Approach. Proceedings of the Samahang Pisika ng Pilipinas. 2016. Available from: https://paperview.spponline.org/proceedings/article/view/355.

[31] Ito K. Stochastic Processes and Their Applications. New York: Springer; 2008.

[32] Gradshteyn IS and Ryzhik IM. Table of Integrals, Series, and Products. San Diego: Academic Press; 1980.

[33] Mazzucchi S. Functional-Integral Solution for The Schrodinger Equation with Polynomial Potential: A White Noise Approach. Infinite Dimensional Analysis, Quantum Probability and Related Topics. 2011; 14(04): 675-688. DOI:

https://doi.org/10.1142/S0219025711004572.

[34] Gemao B and Bornales J. White Noise Path Integral Treatment of The Probability Distribution for The Area Enclosed by a Polymer Loop in Crossed Electric-Magnetic Fields. International Journal of Modern Physics: Conference Series. 2012; 17: 77-82. DOI:

https://doi.org/10.1142/S2010194512007969.

[35] Gemao B, Bornales J, and Loquero M. On Polymer Loop in a Gel Under External Fields: Analytical Approach using White Noise Analysis. IOP Conference Series: Materials Science and Engineering. 2015; 79: 012012. DOI: $\quad$ https://doi.org/10.1088/1757899X/79/1/012012.

[36] Aure RRL, Bernido CC, Carpio-Bernido MV, and Bacabac RG. Damped White Noise Diffusion with Memory for Diffusing Microprobes in Ageing Fibrin Gels. Biophysical Journal. 2019; 117(6): 10291036. DOI:

https://doi.org/10.1016/j.bpj.2019.08.014.
[37] Lü X and Dai W. A White Noise Approach to Stochastic Partial Differential Equations Driven by the Fractional Lévy Noise. Advances in Difference Equations. 2018; 2018: 420. DOI:

https://doi.org/10.1186/s13662-018-1861-y.

[38] Bock W, Grothaus M, and Jung S. The Feynman Integrand for the Charged Particle in A Constant Magnetic Field as White Noise Distribution. Communications on Stochastic Analysis. $\quad 2012 ; \quad$ 6(4): $10 . \quad$ DOI: http://doi.org/10.31390/cosa.6.4.10.

[39] Bock W, da Silva JL, and Suryawan HP. Local Times for Multifractional Brownian Motion in Higher Dimensions: A White Noise Approach. Infinite Dimensional Analysis, Quantum Probability and Related Topics. 2016; 19(04): 1650026. DOI: https://doi.org/10.1142/S0219025716500260. [40] Bock W. Hamiltonian Path Integrals in Momentum Space Representation via White Noise Techniques. Reports on Mathematical Physics. 2014; 73(1): 91-107. DOI: https://doi.org/10.1016/S00344877(14)60034-3.

[41] Violanda RR, Bernido CC, and CarpioBernido MV. White Noise Functional Integral for Exponentially Decaying Memory: Nucleotide Distribution in Bacterial Genomes. Physica Scripta. 2019; 94(12): 125006. DOI: https://doi.org/10.1088/14024896/ab3739.

[42] Bernido CC, Carpio-Bernido MV, and Escobido MGO. Modified Diffusion with Memory for Cyclone Track Fluctuations. Physics Letters A. 2014; 378(30-31): 20162019. DOI:

https://doi.org/10.1016/j.physlets.2014.06.00 3.

[43] Weiss U. Quantum Dissipative Systems. Singapore: World Scientific; 1999. 